\title{
Histological Characteristic that Accompanying with Ovaryfolliculogenisis of Rabbits for Effectiveness Seeds of (Trigonellatibetana)
}

\author{
Hussein Bashar Mahmood ${ }^{1}$, Walaa F Obead ${ }^{2}$, Ghassan A Dawood ${ }^{3}$ \\ ${ }^{1}$ Assist. Prof. Dr., ${ }^{2}$ Lecturer Dr., ${ }^{3}$ Lecturer, Department of Anatomy and Histology/College of Veterinary Medicine/ \\ University of Kerbala
}

\begin{abstract}
Objectives: Alternative plants Medicine has been considered one of the world's most important solutions to female reproductive diseases. The goal of the current study however, was to evaluate the mains histological changes that follow the use of seeds of (Trigonellatibetana) on ovary folliculogenisis.

Method: Twelve's female healthy rabbits, in animal house all experimental animals have been adapted. For this study, animals were taken distributed into two groups, control administrated by distal water $(5 \mathrm{ml} /$ $\mathrm{kg} \mathrm{b.w)} \mathrm{and} \mathrm{treatment} \mathrm{group} \mathrm{was} \mathrm{administered} \mathrm{by} \mathrm{Trigonellatibetana} \mathrm{extract} \mathrm{at} \mathrm{a} \mathrm{dose} \mathrm{of} 2 \mathrm{~g} / \mathrm{kgb}$.w/orally administration during 2 week for 3 time daily.

Results: The present study finding the numerouschanges happened in the ovary, the mains variance has been noticed increase the numbers of primordial and atretic follicles in treatment group and increase in size of follicles. Moreover, the theca interna was thickness and has a thicker layers of collagen than control group.
\end{abstract}

Conclusions: Such results indicate that (Trigonellatibetana) was considered to be suitable for early fertility period arrival.

Keywords: Histological, Trigonellatibetana, folliculogenisis, rabbits.

\section{Introduction}

Nowadays, in world culture, the term alternate solution Medicine has become very popular, focusing on the concept of using the plants for medicinal purposes. But the present absolutely believe that the only medicines we can trust and use are those which come in capsules or medications. And though most of these tablets and capsules that we take and use come from plants during our everyday lives. Medicinal plants were used as raw materials for the extraction process components that were used in the utilization of various drugs. It includes products from plants, as in the case of sedatives, antibiotics and blood thinners. Moreover the active ingredients of Taxol, vincristine, and morphine isolated from foxglove, periwinkle, yew, and opium poppy, respectively ${ }^{1}$. Medicinal plants are incredibly recognized worldwide as a synthetic anti-inflammatory or considered alternative medicine in the word. In addition there are numerous of plants has been used to treatment of ulcer and acidity in stomach as such as Inhibitor pump $\mathrm{H}^{+}$proton ${ }^{2}$. Herbal medicines have a great future as there are approximately half a million species worldwide and most of them have not yet indicted their medical activities and their medical activities may be crucial in the therapy of current or potential experiments ${ }^{3}$. Trigonell is one of the principal family of herbal medicines. The plant's effective medicinal part is its seeds which own fertility hormones such as estrogen and progesterone. It is also used for reduce dysmenorrhea occurrence and wound repair, GIT ${ }^{4,5}$. Furthermore, the administration herbal plants in laboratory animals due to decrease the number of cystic follicles and increase the number of normal follicles. In addition to metabolic modification, there are related changes in the production of reproductive hormones, including the significantly 
increased luteinizing hormone (LH) to folliclestimulating hormone ${ }^{(6,7)}$. Fenugreek conserved good general health, apparently hyperactivity and elevated intake of food, but no major changes in the value in body mass. High doses however significantly decrease the improvement in mature body weight for rats. Fenugreek seeds increase folliculogenysis in mature, perimeter and mature groups but do not affect follicular growth and development likewise, these seeds have estrogen like action ${ }^{8}$. Eventually, the medical plants have a great effectiveness to improve of histological characteristics and due to recover disadvantage in organs. The goal of this study to follow the main stages evolve the follicles and arriving to maturate period early.

\section{Materials and Method}

Twelve healthy female rabbits were chosen and divided in to two groups (control and treatment group). The average weight were [1100-1300] g, breed locally, and were used in this study. Control group [ $5 \mathrm{ml} / \mathrm{kg} \mathrm{b.w}$ ] administrated by distilled Waterand treated group have been given mix of $(2 \mathrm{~g})$ from Trigonellatibetana with $5 \mathrm{ml}$ of distal water after that administration $[5 \mathrm{ml} / \mathrm{kg}$ b.w] orally during 14 day for 3 time daily ${ }^{(9)}$. Ovary samples were then kept for 72 hours in $10 \%$ formalin. Hematoxyline, eosin and Masson's trichrome stain were used in the samples with routine histological technique: to differentiate tissue components, connective tissue fibers (collagen), fibrin, and muscles ${ }^{(11)}$. Themeasuring of theca interna was performed using the average of (4) microscopic fields for each histological section representing $1.13 \mathrm{~mm} 2$ below $10 \mathrm{X}$, selecting (5) histological section. After which end up taking the arithmetic mean in all fields and convert the $1 \mathrm{~mm} 2$ arythmically ${ }^{(10)}$.

\section{Results and Discussion}

Histological Features: The anatomical features for the rabbit ovary were elongated shape, located in pelvic region and pushed slightly to the abdomen cavity. Likewise, the ovary in control rabbit had smooth texture and longer while the ovary in treatment group was rough surface, these result akin with ${ }^{(11)}$ in female Rabbit and ${ }^{(12,13)}$ in female Hamster who stated that the effect of medicinal plant in anatomical characteristics. While this results contrasting with ${ }^{(14,15)}$ in Albino rat which finding different results and considered these medicinal plant not affecting on anatomical features.

Generally, during inspection of all histological sections of ovary observed many variances between two groups: The stroma of ovary in the control group was distinguished by existence a numbers of primordial follicles closed to germinal layer, these follicle were a less number moreover, more follicles in this group were primary and secondary stage and atretic follicles observed rarely (Figure,1). The ovary in treatment group had a large numbers of primordial follicles which, spread a long sheet of germinal layer. On the other hand the ovary of treatment group was distinguished by the presence of large numbers of mature follicles that distributed in all region of stroma (Figure, 2). These results occur as high level sexual hormones as Estrogen and Progesterone this consequences similar with $^{(16)}$ who show that trigonellaseeds with relatively normal follicular maturation increase the normal of folliculogenisis. Mature ovaries secrete adequate quantities of oestrogen reinforce by crude trigonella seeds, resulting in significant increases in growing follicles, with increase in total ovarian structures.

The present study was finding the theca interna in normal ovaries have a thin and consist of (3-6) coil around ovarian follicles, thickness about $(50 \mu \mathrm{m})$ while the theca interna in treatment ovaries became a thick layer about (10-12) coil and thickness about $(100 \mu \mathrm{m})$. These finding akin with $^{(17)}$ which mention that the administrated medical plant in female rats this process lead to increase size of the ovaries structures (Figure, 3,4).

The present study was showing the variance in quantity of collagen fibers through distribution of connective tissue beneath germinal layer and intermingled with theca interna. There are massive amount of collagen fibers in treated ovaries while the control ovaries have less quantity (Fig, 5,6). These result was happing probably for impact increase the follicles size to support Graafian follicles, this finding akin with ${ }^{(18)}$ who has reported that the increase in the thickness of theca interna shown in can play a role in steroidogenysis. This is because of ovarian estrogen, is secreted by theca interna, 


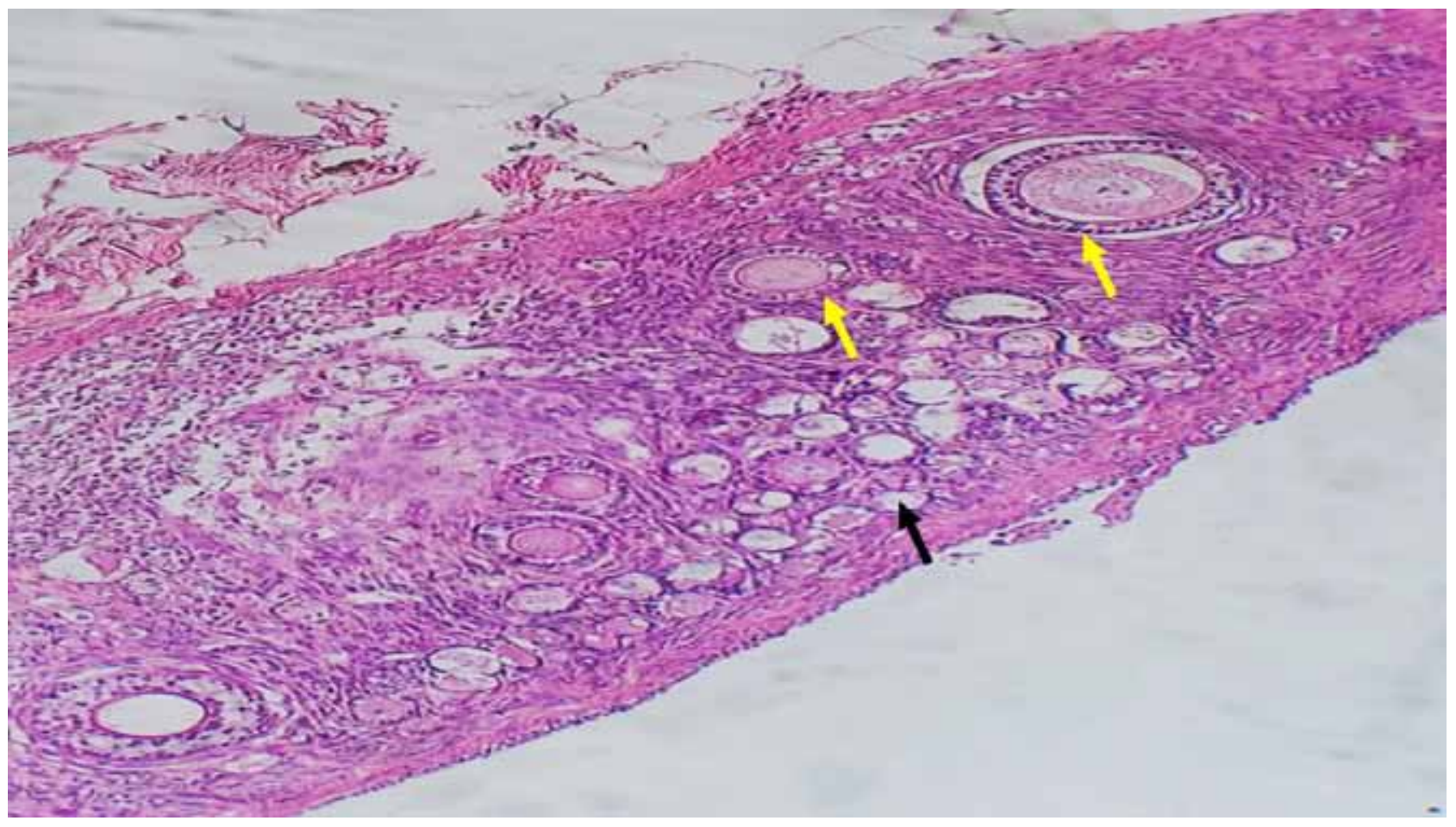

Figure, 1: Control group showing the stroma of ovaryhave premordial (black arrow), prinary and secondary follicles (yellow arrow). H\&E stain.40X.

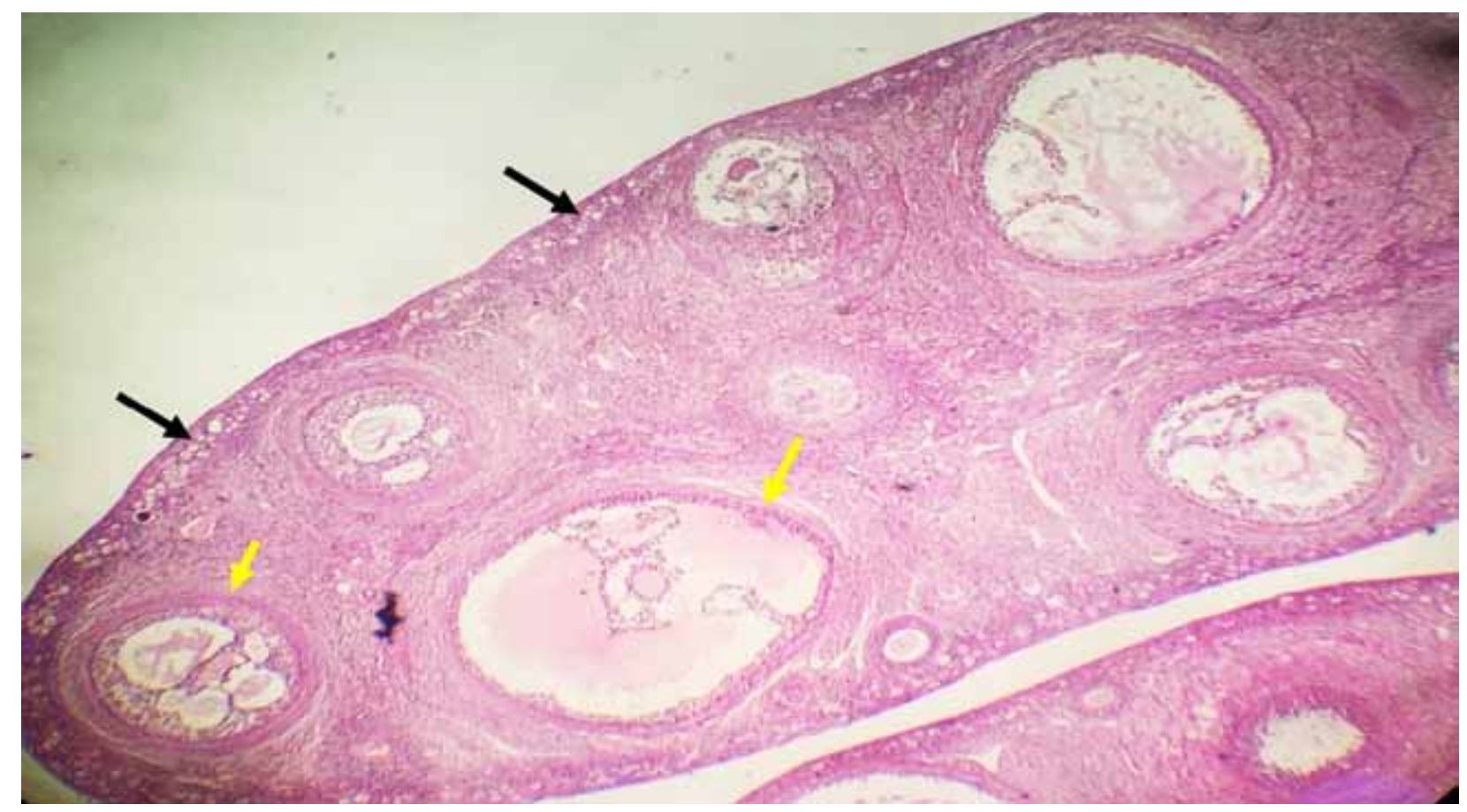

Figure, 2: Treatment group showing the ovrary have a large number of perimordial follicles (black arrows) and rarly atretic follicles(yellow arrow) H\&E stain.40X. 


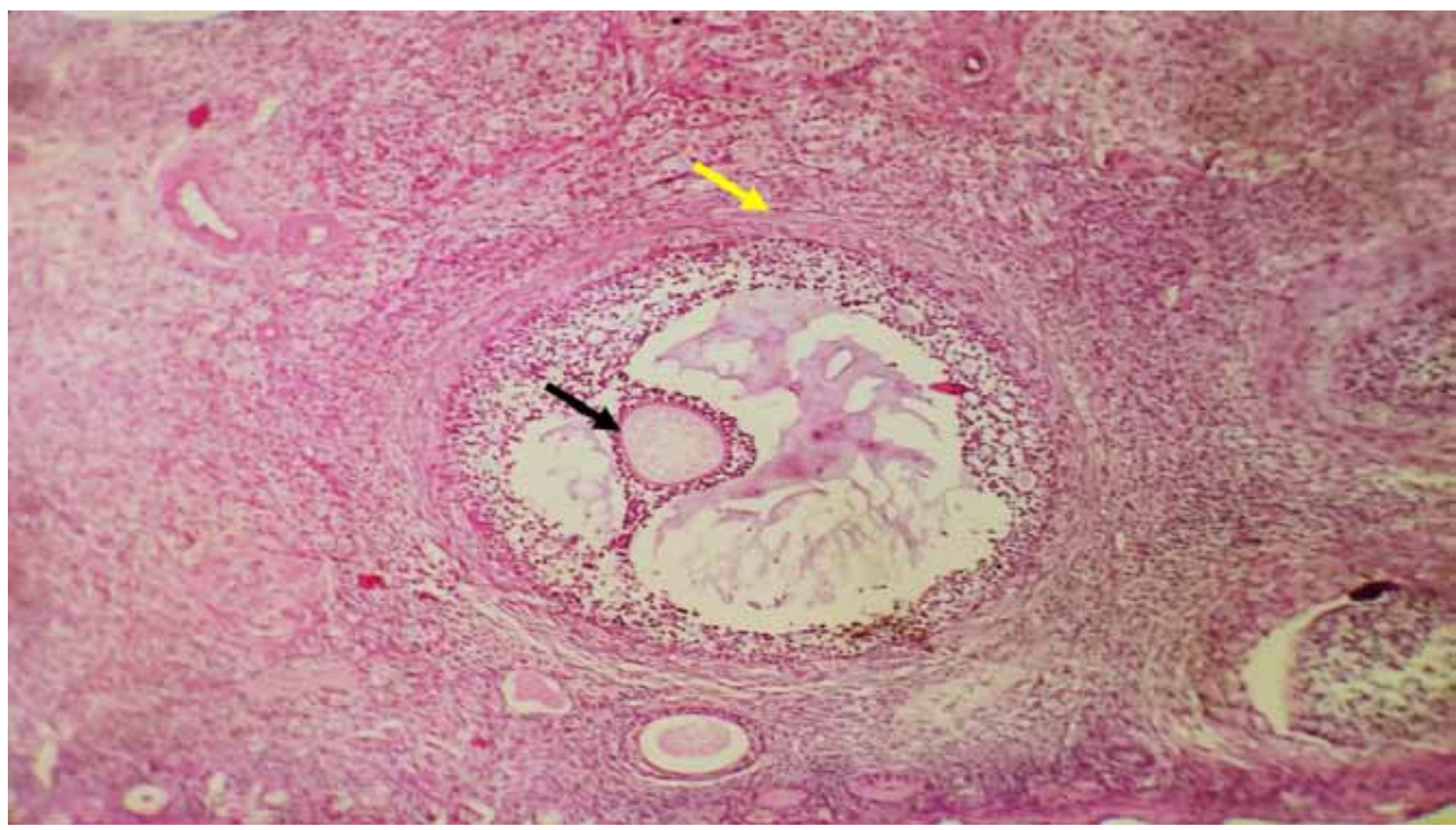

Figure, 3: Control group showing the mature follicle surrounded by a thin of theca interna (yellow arrow) with spherical ooyte (black arrow). H\&E stain.100X.

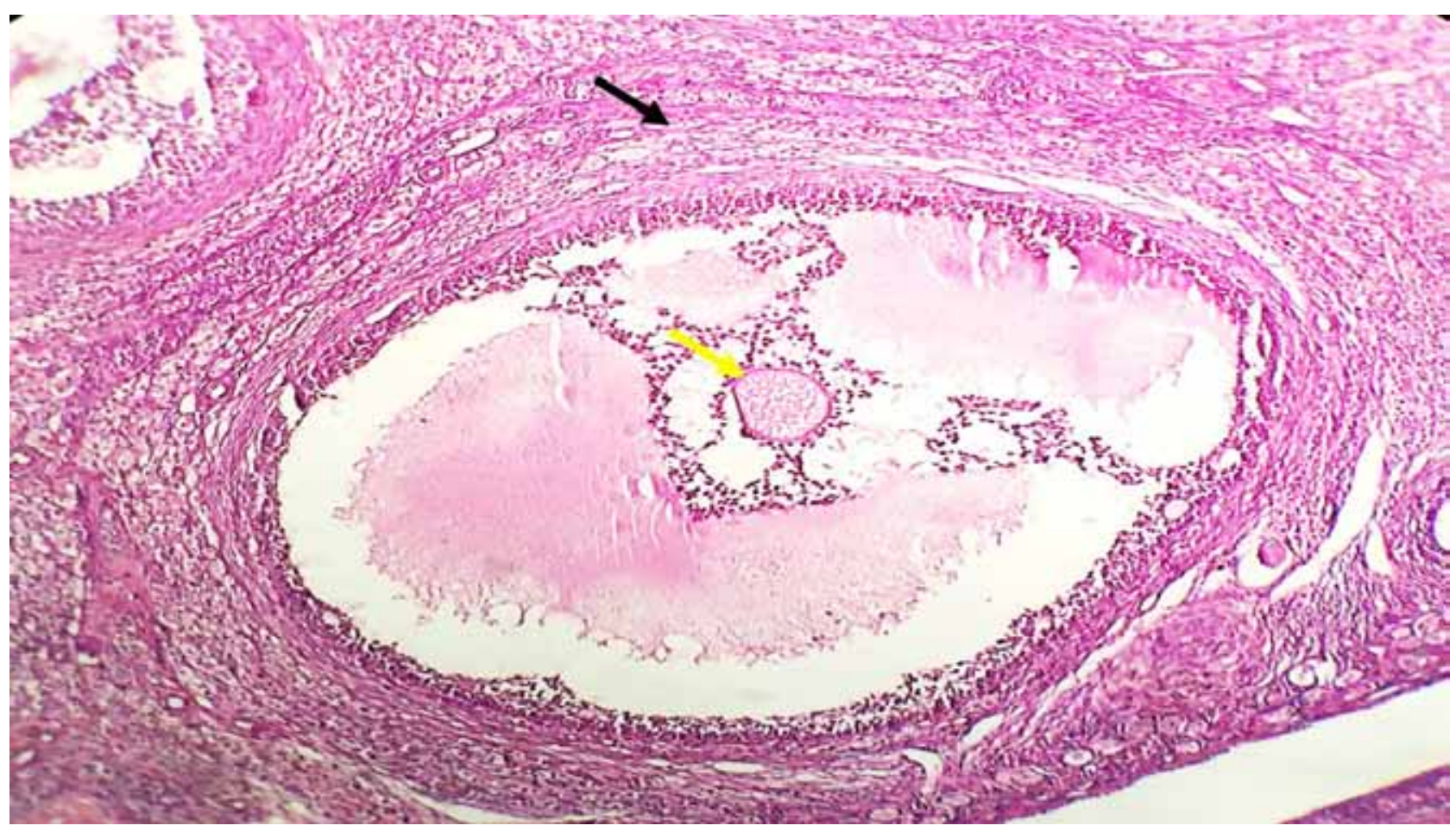

Figure, 4: Treatment group showing the ovrary have a thich layer of theca interna (black arrow) H\&E stain.100X. 


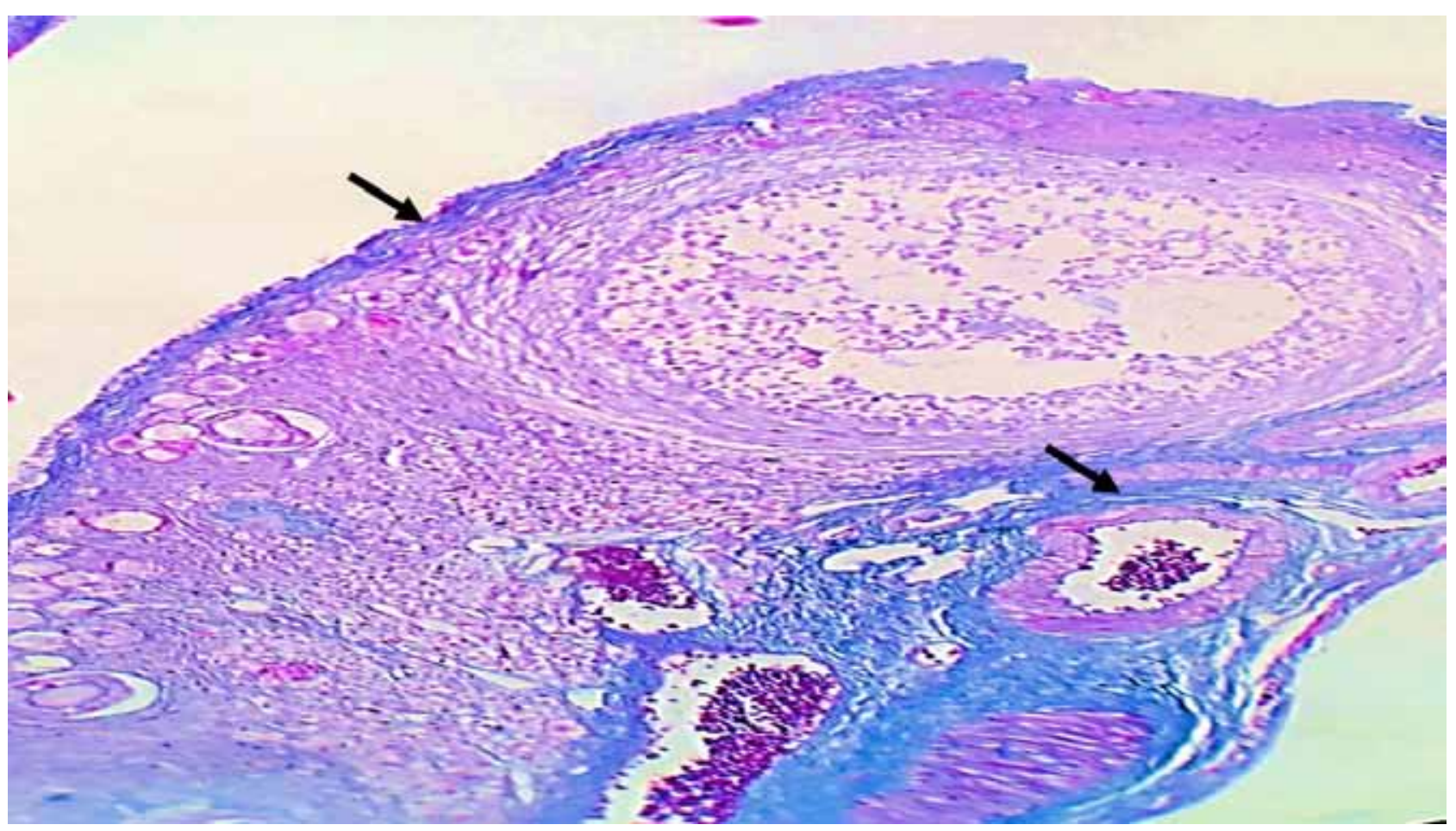

Figure, 5: Control group showing the amount of connective tissue spread ander germinal layer and blood vessels (black arrow). Masson trichrome stain.100X.

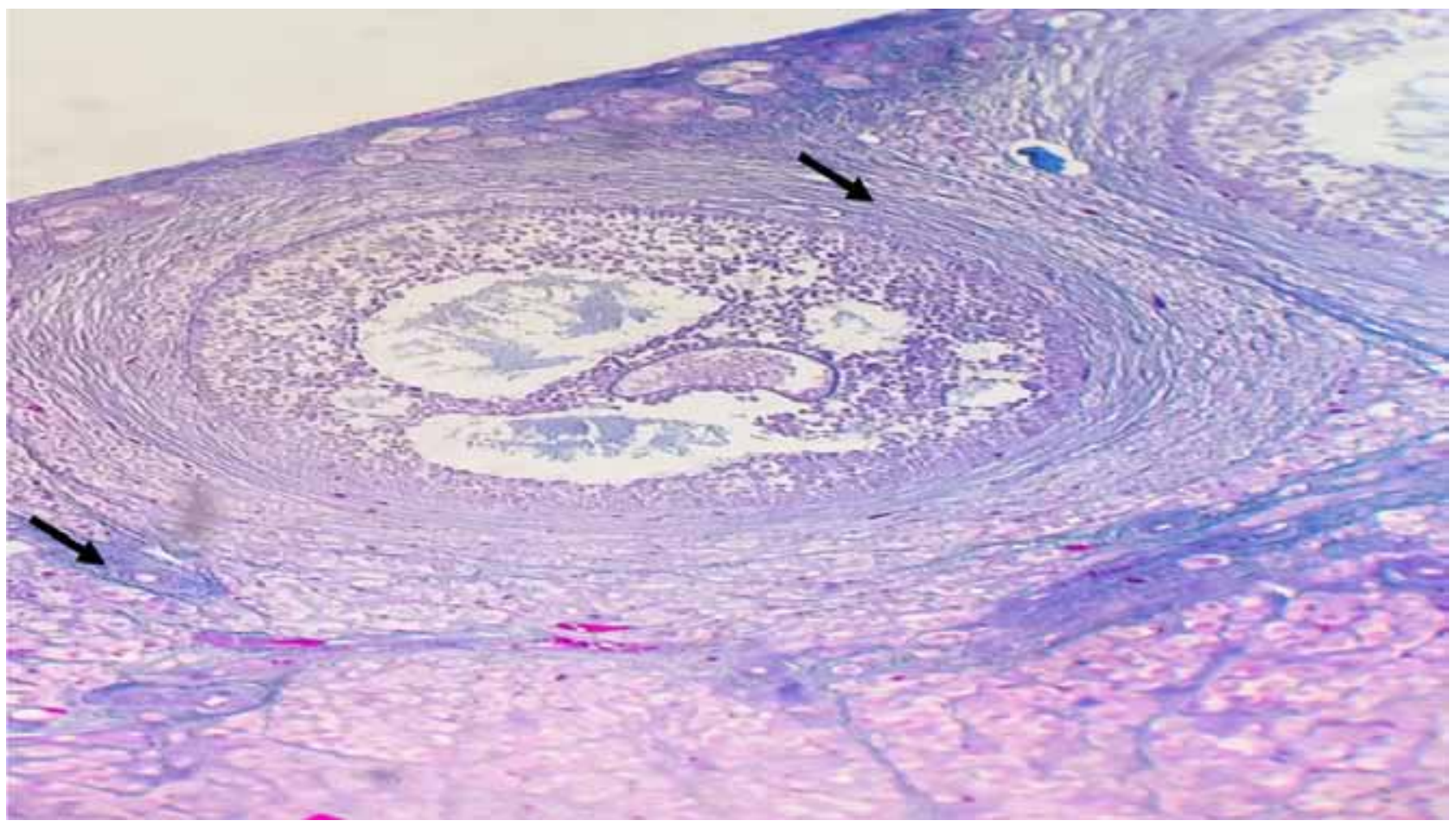

Figure, 6: Treatment group showing the ovrary have a large amount of connective tissue intermingled with theca interna (black arrow) Masson tirchrome stain. 100X. 


\section{Conclusion}

Such results indicate that (Trigonellatibetana) was considered to be suitable for early fertility period arrival.

Financial Disclosure: There is no financial disclosure.

Conflict of Interest: None to declare.

Ethical Clearance: All experimental protocols were approved under the University of Kerbala and all experiments were carried out in accordance with approved guidelines.

\section{References}

1. Rasool HB. Medicinal Plants (Importance and Uses). Pharmaceut Anal Acta.2012; 3: e139.

2. Mahmood HB, Dawood GA, Bargooth AF. Histological Investigations for CordiaMyxaDuring the Treatment of Gastritis in Local Rabbits. Jinu. M, Thankamma. P. George, NA Balaram, Sujisha. SS 2. Profile of Burn Deaths: A Study Based on Postmortem Examination of Burn Cases at RNT.2020; 20(3): 453.

3. Omo Z, Uwadia C, Ayo C, Marika V, Chieze F. Multimedia based medicinal plants sustainability management system. International Journal of Communication Disease Science. 2011; 8 (3): 1694 -1714 .

4. Sharma RD, Raghram TC.Effect of fenugreek seeds on blood glucose and serum lipids in type 1 diabetics. Eur J ClinNutr. 2000;44:301-306.

5. Eman A. Pathological and Biochemical Studies on the Effect of TrigonellafoenumGraecum and LupinustermisinAlloxan Induced Diabetic Rats. World Applied Sciences Journal 2011;12(10):18391850.

6. Abtahi-Eivari S, Moghimian M. The effect of Galegaofficinalis on hormonal and metabolic profile in a rat model of polycystic ovary syndrome. INTERNATIONAL JOURNAL OF WOMENS HEALTH AND REPRODUCTION SCIENCES.2018; 6(3): 276-282.

7. Pergialiotis V, Konstantopoulos P, Prodromidou A, Florou V, Papantoniou N, Perrea DN. Management of endocrine disease: the impact of subclinical hypothyroidism on anthropometric characteristics, lipid, glucose and hormonal profile of PCOS patients: a systematic review and meta-analysis. Eur J Endocrinol. 2017;176(3):R159-r166.
8. Petiti P, Sauvaire Y, Ponsin G, Manteghetti M, Fave A, Ribes G. Effect of fenugreek seeds extract on feeding behavior in rats: metabolicendocrine correlation. PhamacolBiochemBehav. 1993;45:369- 374.

9. Sakran AM, Faragalla HE, Ibrahim AY, Alkushi AG. Effect of fenugreek seeds on rat's ovary: Histological study. Int. J. Anat. Res.2016; 4(1): 1945-53.

10. Batah LA, Mahmood HB, Obead WF. Anatomical, Histological and Histochemical Investigation of Soft Palate in Cat (FelisCatusDomesticus.L). Indian Journal of Forensic Medicine \& Toxicology. 2020; 14 (3): 237-241.

11. Kaisser A, Gabari A, Habeb M, Majid M. Evaluation of the potential activity effect of Fenugreek (Trigonellafoenum) in female rabbits. Iraqi Journal of Biological Sciences.2006; 7 (3): 31 - 42.

12. Bancroft J, Gamble M. Theory and practice of Histological techniques. Churchill Livingstone Elsevier. Sixth edition. UK.2008.

13. More A, Moro F, Rott M, Hemi J. Effect of Fenugreek (Trigonellafoenum) on Metabolism and ovary structure in Hamster. Asian Journal of Reproduction and Nutrition.2005; 45 (4): 40 - 48.

14. Nassem M, Khaki A, Ahmadi H, Rastgar H. Effects of ginger on sex hormones andovary development in female Albino rat. Iranian Journal of Medical Science.2009; 8 (4): 118 - 124

15. Verma N, Amresh P, Sahu N. Antihyperglycemic activity,HematologicaleffectsandHistopathological analysis of Ginger and Fenugreek in female rats. Asian Journal of Biological Medicine.2012; 8(3): $78-88$.

16. Maeda KI, Ohkura S, Tsukamura H. Physiology of Reproduction. In Krinke GJ. The Laboratory Rat .New York: Academic Press 2000;145-176.

17. Abtahi-Eivari SH, Moghimian M, Soltani M. The effect of Galegaofficinalis on hormonal and metabolic profile in a rat model of polycystic ovary syndrome. INTERNATIONAL JOURNAL OF WOMENS HEALTH AND REPRODUCTION SCIENCES. 2018; 6(3): 276-282.

18. Daryl K, Granner MD. Hormones of the gonads. In: Murray RK, Mayes PA, Granner DK and Rodwell VW (ed.s). Harper's Biochemistry. Twenty second ed. Appleton and Lange. Norwalk, Connecticut/ Los Altos, California, 1993;516-529. 